\title{
Hungría en la transición. A propósito del I seminario Hispano-Húngaro sobre desequilibrios regionales
}

\author{
José SÁNCHEZ SANCHEZ
}

Del 26 de agosto al 2 de septiembre de 1990 se celebró en Hungria un seminario sobre la temática de los desequilibrios regionales. Participó un grupo de investigadores del Instituto de Estudios Regionales de la Academia de Ciencias de Hungria (Magyar Tudományos Akadémia Regionális Kutatások Központja) y otro grupo de profesores del Departamento de Geografía de la Universidad Nacional de Educación a Distaricia (UNED); por parte húngara, los doctores Györgyi Barta y Pál Beluszky, de Budapest; János Rechnitzer, Irén Kukorelli, Edit Kranner y Mihály Lados, de Györ; János Vinzce, Éva Fekete, Szabó Györgyné e István Mezei, de Miskolc; y por parte española, los doctores Julián Alonso, Blanca Azcárate, Tomás Franco, José Sánchez y Antonio Zárate.

Las sesiones se desarrollaron en tres de las sedes regionales del Instituto de Estudios Regionales (Budapest, Györ y Miskolc), y los organizadores húngaros tuvieron la gentileza de mostrarnos sobre el terreno y a lo largo de las jornadas de trabajo algunos de los principales problemas que afectaban a su pais en los inicios de la dura transición a un nuevo sistema político, económico y social; y, de manera particular, los referidos a las regiones visitadas. Por su parte, los profesores de la UNED expusimos diversos aspectos de los desequilibrios regionales en España y las perspectivas futuras, tras su incorporación a la Comunidad Económica Europea ${ }^{2}$.

' Departamento de Geografia, UNED.

2 Las comunicaciones han sido objeto de una publicación, editada por el Instituto de Estudios Regionales de la Academia de Ciencias de Hungria y la UNED. 


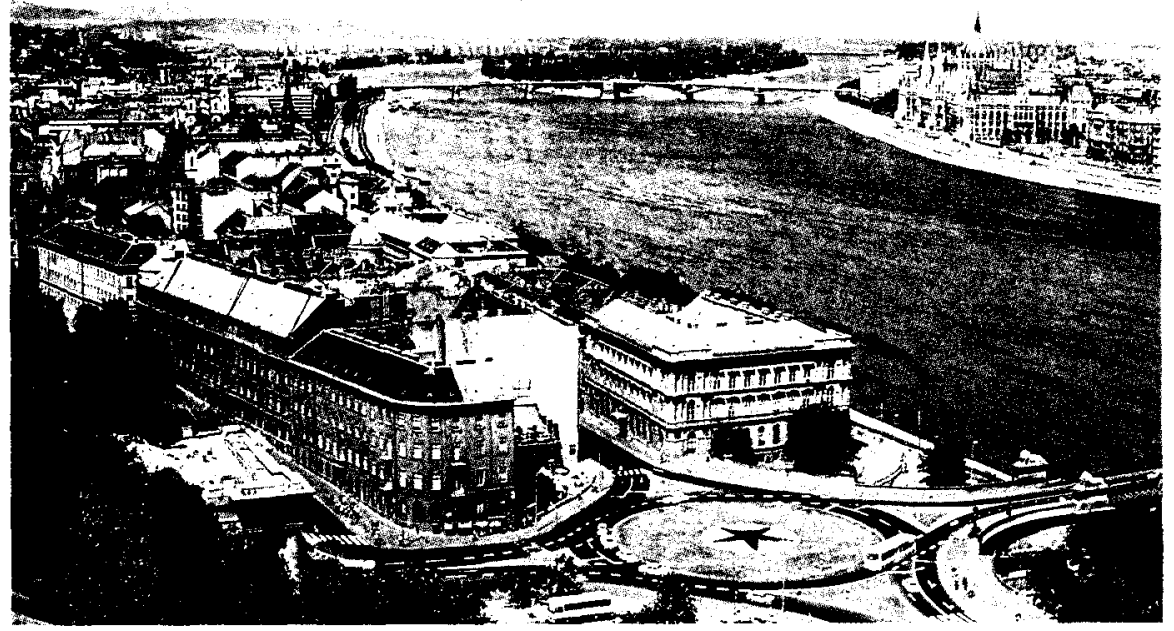

Foto 1. Vista panorámica de Budapest. El Danubio, protagonista indiscutible de la ciudad, separa a Buda (izq.) de Pest (dcha.); al fondo, la isla de Margarita y el puente del mismo nombre. (Foto: José Sánchez).

El Instituto de Estudios Regionales fue creado en 1984 por el geógrafo y académico György Enyedi que, desde la fundación, ha sido su director. Nació como consecuencia de las preocupaciones derivadas de los desequilibrios territoriales y como centro de investigación interdisciplinar en torno a los problemas del desarrollo regional; está integrado en la Academia de Ciencias de Hungría, de donde los investigadores dependen administrativa y económicamente, pero el funcionamiento del Instituto debe mantenerse mediante los recursos generados por el trabajo de los propios investigadores. Entre los 90-100 miembros que lo componen figuran geógrafos, economistas, sociólogos, estadísticos, juristas, historiadores, etnólogos y titulados en ordenación del territorio. Se basa en una estructura descentralizada: la sede central está en Pécs y los centros regionales, con un alto grado de autonomía, se hallan, además de en Pécs, en Budapest, Györ, Miskolc, Kecskemét y Békéscsaba.

Como nos explicaba el doctor Enyedi en la sesión de inauguración, el Instituto de Estudios Regionales es uno de los pocos ejemplos en los que Budapest no es sede central. Hacía alusión implícita a la enorme fuerza centralizadora de la hermosa ciudad. 


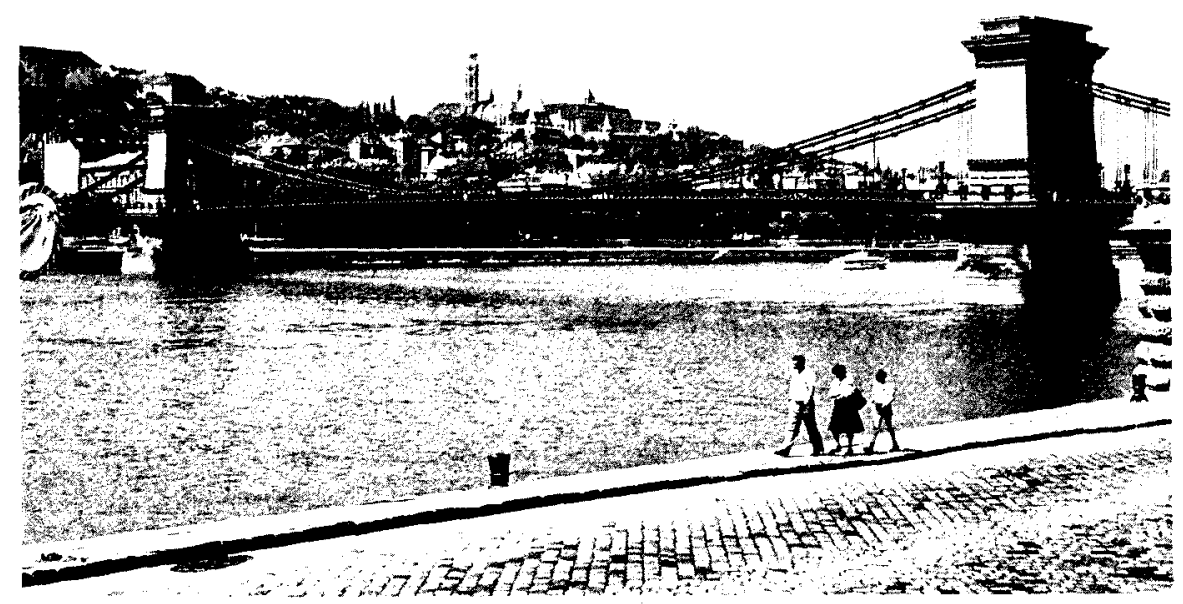

Foto 2. Vista de Buda desde Pest. El Puente de Cadenas (Láncshid) fue el primer puente de piedra, construido por ingenieros ingleses (1840-1849) para unir las dos ciudades que dieron lugar a Budapest. Al fondo, la iglesia de Matias en el Bastión de los Pescadores. (Foto: José Sánchez).

El Seminario se inició con la visita a Budapest: el Danubio, como protagonista del hecho urbano; el Parlamento, como protagonista del cambio político, la Plaza de los Héroes, memoria del lejano pasado siempre presente en este pais; Buda, con su cálido sabor histórico, y la incomparable panorámica desde el Halászbástya o Bastión de los Pescadores; Pest, con el Duna-part, la animada Váci Utca, la encantadora Plaza de Vörösmarty, el Museo de Bellas Artes... . Para el turista extranjero, Budapest casi lo es todo en Hungría (foto 1 y 2). Así lo refleja la inmensa masificación de un turismo de paso, organizado y dirigido por las compañias operadoras, que materialmente saturan el centro de la capital en cada periodo de vacaciones (Hungría recibe unos 18 millones de turistas al año). Pero Budapest no es sólo el centro tomado por los visistantes que se van relevando cada dos dias; es también el conjunto de los montes de Buda, los baños turcos de aguas termales a la orilla del Danubio, la Isla de Margarita, los densos barrios periféricos formados por «lákotelep" o enormes bloques de viviendas de 45 metros cuadrados, y todos iguales... 


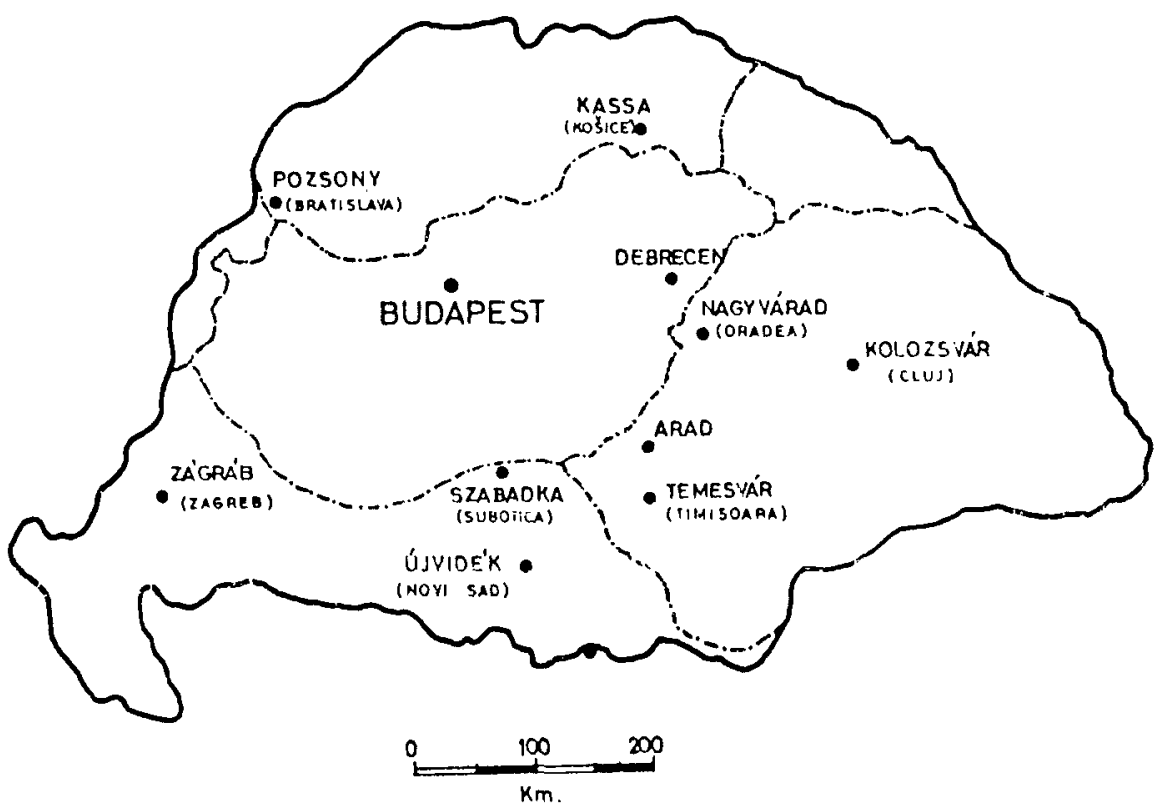

Fig. 1. Grandes Ciudades Húngaras antes de 1920.

Budapest es, de hecho, una gran metrópoli centroeuropea; pero, con una concentración desmesurada de funciones, resulta demasiada capital para la pequeña Hungría que conocemos. El desmembramiento ocurrido en 1920, en el tratado de Trianon, tras la primera guerra mundial, dejó reducido el pais a menos de la tercera parte de su territorio anterior, perdiendo el $64 \%$ de su población. Las consecuencias de orden geográfico fueron extremadamente graves: perdió todas las montañas que circundan la cuenca de Panonia, especialmente los Cárpatos; el país quedó reducido al fondo de esta cuenca, adquiriendo el actual carácter casi exclusivo de llanura, con problemas de aridez en su parte oriental y sin el control de las cabeceras de los ríos que atraviesan estas regiones; muchas de las materias primas quedaron también fuera de sus fronteras; las principales líneas férreas resultaron cortadas por las nuevas fronteras y surgieron graves problemas de interrelación entre las regiones periféricas; se rompieron las unidades regionales de mercado y las grandes ciudades que, en la red urbana de Europa Central, ejercian de contrapeso a Budapest (Bratislava, Kosice, Cluj, Oradea, Arad, Timisoara, Subo- 
tica y Zagreb) quedaron a partir de entonces fuera de sus fronteras (fig. 1), mientras que las más pequeñas que siguieron siendo húngaras (Miskolc, Debrecem Szeged, Pécs y Györ) se vieron desprovistas de sus tradicionales y naturales áreas de influencia $y$, por lo tanto, condenadas al más gris estancamiento (fig. 2).

En este contexto de fragmentación del país, Budapest, como Viena - más todavía que Viena, se convierte en una macrociudad, con una capitalidad hipertrofiada, acaparadora de funciones, que transmite a la red urbana húngara el carácter negativo de la macrocefalia.



$\sum$ Territorios perdidos por Hungria en el tratado de Trianón.

- Grandes ejes ferroviarios cortados.

-) Ciudades con área de influencia reducida por la nueva frontera.

Fig. 2. Territorios perdidos en el Tratado de Trianon y desajuste en la red ferroviaria $y$ en el sistema urbano. 
Budapest constituye, pues, el elemento mayor de la geografia y de la historia húngara. Los dos millones de habitantes representan el $20 \%$ de la población del país. Y la política de industrialización forzada propugnada por el socialismo en los años 50 y 60 ha conducido a un reforzamiento del papel dirigente y prepotente de Budapest dentro de Hungría. A pesar del plan de control de su crecimiento, mediante la descentralización industrial, aprobado en 1971, la ciudad concentra el $40 \%$ de los obreros húngaros, el $50 \%$ de la industria textil, el $55 \%$ de la producción de maquinaria, el $65 \%$ de los productos farmaceúticos; también el $66 \%$ de los estudiantes y la mayor parte de los investigadores e intelectuales.

Este abultado peso demográfico, económico e intelectual de Budapest ha transcendido desde finales del siglo XIX a la estructura de los partidos políticos y hoy, cuando ha habido que rehacer la vida política con un sistema pluripartidista, ha vuelto a reproducirse esa misma dicotomia Budapest-Provincias que pesa negativamente en la conciencia nacional.

Los dos partidos mayoritarios recogen, a grandes rasgos, esta doble realidad. El Magyar Democrata Fórum (MDF), Foro de los Demócratas Húngaros, ganador de las primeras elecciones libres de 1989, representa la hungaridad tradicional, los valores de la patria, sentimientos más apegados a la tierra y que suelen permanecer vivos en los habitantes de las provincias; este partido se ve complementado en el espectro político y apoyado en la actual coalición por el Partido Popular Demócrata Cristiano y por el Partido de los Pequeños Agricultores. El segundo partido mayoritario es el Szabad Democrata Szövetsége o Unión de Demócratas Libres (SzDSz), complementado de forma natural por la Asociación de Jóvenes Demócratas, es un partido más liberal, que encuentra a una buena parte de sus seguidores en el medio urbano, principalmente Budapest, se siente menos pegado a las tradiciones y propugna un mayor cosmopolitismo de la sociedad húngara.

Este peso del pasado histórico de Hungría, los imperativos del modelo económico socialista $y$, en cierta manera, la incapacidad de los agentes políticos para afrontar estas realidades y para promover y llevar a cabo una eficaz política de desarrollo regional (fig.3), son los aspectos que nos expuso en Miskolc Pál Beluszky con su comunicación "Desventajas de la localización territorial y su tratamiento en Hungría". Con tono crítico responsabilizaba a la gestión comunista del grave estado actual de los desequilibrios regionales en Hungria. $Y$ en la misma sesión, István Mesei nos explicó algunos aspectos de la transición politica en la provincia de Miskolc, con un mayor protagonismo del MDF. 


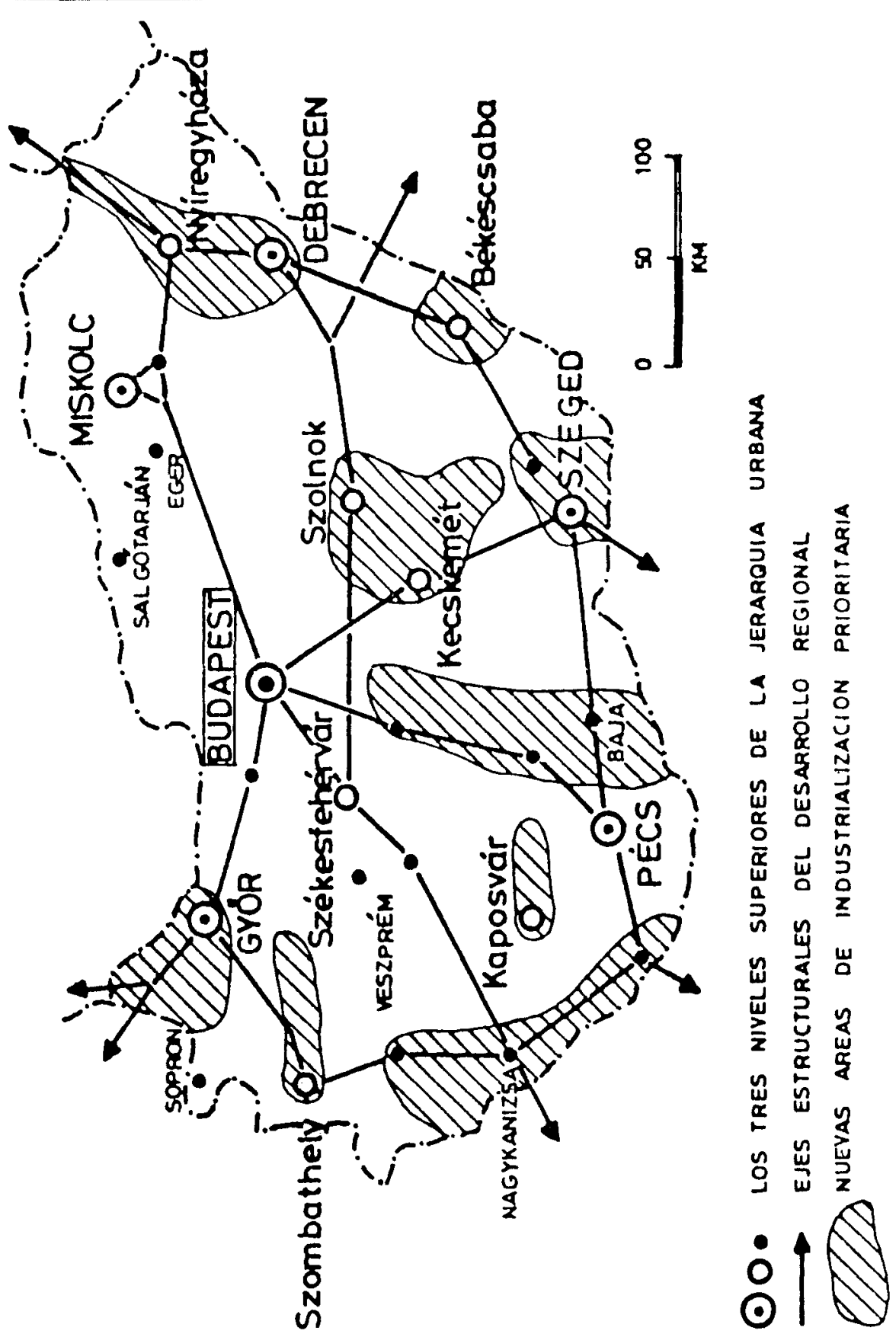

Fig. 3 Hungria, ordenación del territorio según el plan de 1971. 
Tras la inauguración del Seminario en la sede del Instituto en Budapest, nos trasladamos a la ciudad de Györ, capital de la región del Transdanubio-Norte, que se extiende desde las alturas de los montes Bakony hasta el Danubio, frontera con Checoslovaquia por el norte, y hasta el limite con Austria, por el oeste. Alli el equipo de investigadores del centro de Györ, dirigidos por János Rechnitzer, nos expuso algunos de los temas en los que últimamente está trabajando.

Györ (135.000 habitantes) es la capiial de una rica región agrícola, Kisalföld, de fértiles suelos e índices de pluviosidad satisfactorios, donde se han desarrollado algunas de las más famosas cooperativas agrícolas de Hungría, como la de Babolna. Es también sede de una industria de transformación importante, textil y material de transporte, como la fabricación de los camiones y tractores Rába, hoy asociada a la firma Volvo. Se beneficia igualmente de la proximidad al Burgerland austriaco, con el que siempre ha tenido estrechas relaciones. Desde principios de los años ochenta el proceso de apertura de Hungria ha intensificado estas relaciones y Györ ha desarrollado su sector servicios, tanto por la afluencia de austríacos que buscan en esta ciudad precios más bajos que en su país (algunos artículos de consumo, restaurantes, médicos dentistas, peluqueros, esteticistas, mecánicos, etc), sino también por su situación en el centro de la ruta Viena-Budapest, uno de los ejes importantes del turismo europeo en los últimos años.

Teniendo en cuenta que el Transdanubio-Norte presenta en esta etapa de transición las mejores condiciones para la renovación económica, el centro de investigación de Györ ha escogido como una línea de trabajo la difusión de las innovaciones, como factor de desarrollo regional, y realiza la investigación aplicada en su ámbito de influencia que es la región del Noroeste húngaro.

Su director, János RECHNITZER, habló de "Las condiciones y posibilidades de la difusión de las innovaciones", lo que en realidad fue una reseña de los resultados provisionales del programa de investigación, ya bastante avanzado. Se refirió al concepto de innovación desde el punto de vista de la ciencia regional e hizo referencia a la metodología de su investigación. Basándose en los distintos portadores de innovación, aludió a su aparición y difusión y a los factores que las determinan; entre estos, citó al capital humano, la informática, la difusión de pequeñas empresas, de empresas mixtas y de instituciones bancarias, y a los factores sociopolíticos, como los más significativos.

Las otras tres comunicaciones del grupo de Györ se refirieron a tres aspectos concretos de la difusión de las innovaciones. Irén KUKORELLI se 
refirió a los elementos portadores de innovación en tres ciudades del área minera de Tatabánya, concretamente las de Tatabánya, Tata y Oroszlány, que en el periodo del desarrollo forzado de la industria pesada (años cincuenta y sesenta) pasaron de ser pueblos mineros a convertirse en ciudades con gran concentración de población. Sumida hoy en grave crisis, la zona minera de Komaron y las tres ciudades en cuestión, con saldo migratorio negativo desde 1985, están necesitadas de una revitalización para la cual se buscan los factores internos y externos que la hagan posible. En este período de la transición política, el impulso venido hasta ahora desde el centro de decisiones de Budapest se va debilitando. De área preferente para las inversiones se ha convertido en área de crisis, de escaso interés para las inversiones del centro que, en relación al desarrollo económico, piensa de diferente manera. En esta situación cobra relevancia el aprovechamiento de todas las fuerzas internas innovadoras que existan: el sistema de funciones adaptado a una red de poblaciones policéntrica, las empresas y la mano de obra. La exposición de la Dra. Kukorelli se centró en el problema de la coordinación del sistema de funciones entre las tres ciudades relativamente próximas.

Edit Kranner aludió al «Papel de la enseñanza y del potencial intelectual en el desarrollo de las innovaciones en las tres ciudades de Tata, Tatabánya y Oroszlány", explicando el importante papel del potencial intelectual como portador de la innovación y la necesidad de que el sistema de educación-enseñanza potencie el desarrollo cultural y socioeconómico. $Y$, como contraste, nos hablaba de la grave deficiencia de las instituciones educativas y culturales en las tres ciudades citadas, desde la educación básica y secundaria a la enseñanza superior, prácticamente ausente de ellas.

La tercera comunicación que se presentó en Györ fue la de Mihály LADOS que hacia referencia a una investigación sobre la actividad empresarial de los Ayuntamientos. En la fase avanzada de la apertura húngara, a partir de 1985, era importante toda iniciativa empresarial. $Y$ en un país que todavia no habia eliminado las limitaciones a la empresa privada, a pesar de los avances conseguidos desde el establecimiento del Nuevo Mecanismo Económico en 1968, la capacidad empresarial de los Ayuntamientos podía ser decisiva en las pequeñas ciudades. Este tema de interés excepcional en la Hungría de los años ochenta no ha perdido relevancia después del cambio a la economía de mercado, ya que para muchas ciudades inferiores a 40.000 habitantes sigue teniendo gran significación, desde el punto de vista de la creación de actividad y de la estimulación del desarrollo local. Según el Dr. Ládos, en la Hungría de la transición las actividades empresariales de los Ayuntamientos no han lle- 


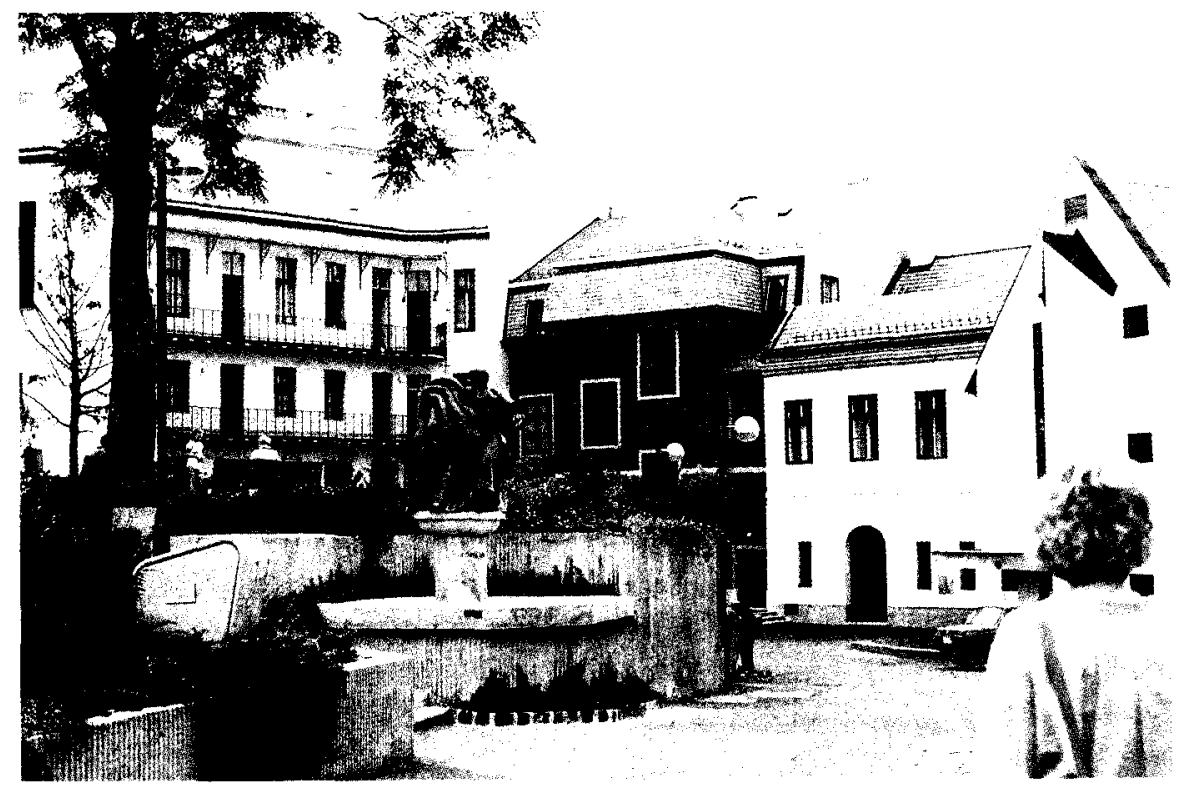

Foto 3. Györ es la capital de Kisalföld en el Noroeste de Hungria, una región dinámica que se beneficia de su proximidad con Austria. En la foto, un rincón de su centro histórico renovado. (Foto: José Sánchez).

gado a desarrollarse suficientemente, no sólo por la existencia de factores básicos negativos, como la falta de propiedad de los entes locales autónomos, infraestructura deficiente, ausencia de marco jurídico-organizativo, etc., sino también porque ha fallado la preparación profesional de los gestores municipales.

La visita a la ciudad de Györ nos descubrió un centro histórico exquisitamente renovado, merecedor en 1987 de un premio europeo a la reconstrucción de cascos históricos (foto 3 ).

Györ, como todas las ciudades húngaras tiene los barrios tipicos de las ciudades socialistas (foto 4) y una amplia franja rururbana que, por la carretera que lleva a la ciudad episcopal de Veszprén — hacia el sur-, se prolonga hasta Pannonhalma, con numerosas casas modernas intercaladas entre las tradicionales (foto 5); lo cual denota la existencia de un sector de población desarrollado en los años setenta y ochenta, relativamente rico, procedente de los pueblos y pluriempleado en la ciudad. Pannonhalma es una abadía benedictina fundada en el 996 por Geza, padre de Esteban I. Está íntimamente unida al sentimiento nacional húngaro, 


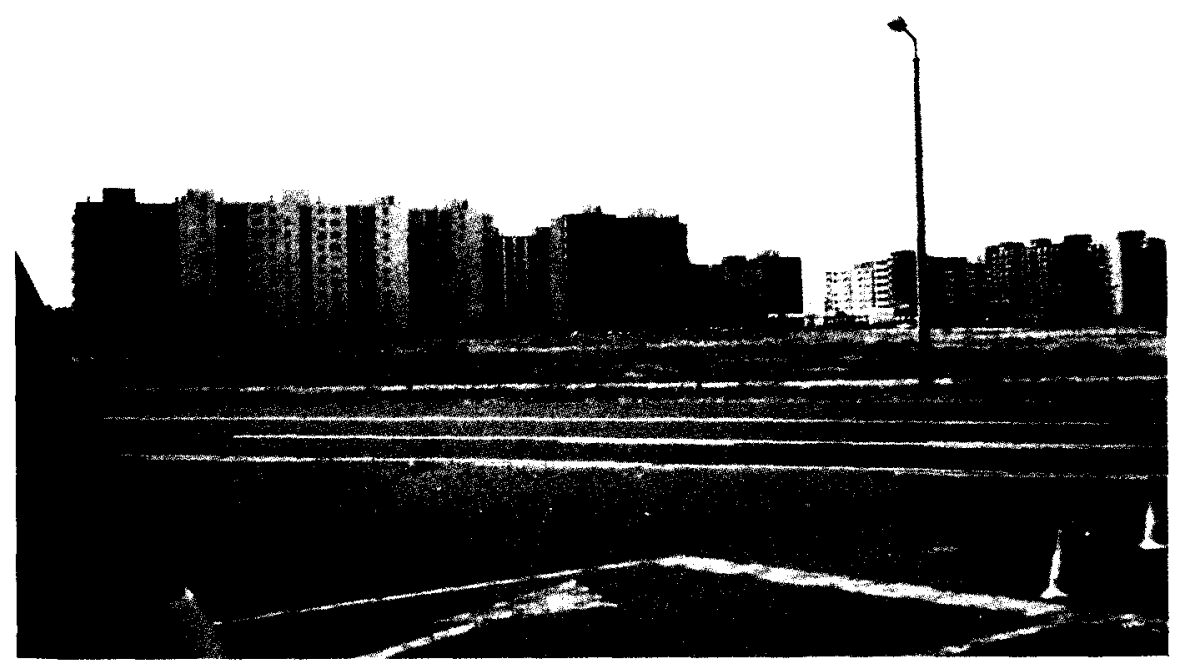

Foto 4. Grandes bloques ("lákotelep") de un barrio periférico de Györ; éstos pertenecen a la última generación; para romper la monotonia a cada bloque se le ha dado un color diferente. (Foto: Blanca Azcárate).

porque ha sido testigo y símbolo de la historia de Hungria, con sus crisis, invasiones y reconstrucciones. Esteban I, fundador del Estado, fue coronado rey en el año 1000 y Pannonhalma fue consagrado monasterio en el 1002. Desde su fundación está unido al proceso de cristianización y lo que ello supone en la Edad Media de occidentalización y europeización.

La transición política ha vuelto a colocar a San Esteban en el lugar que siempre habia tenido: una posición privilegiada en la jerarquía de los valores nacionales y de la tradición cristiana. Con la instauración del socialismo, el 20 de agosto - fiesta de San Esteban- fue declarado fiesta nacional, no por el Rey Santo, sino por conmemorar la fecha de aprobación de la constitución socialista; la festividad cristiana de San Esteban quedaba asi encubierta con otra fiesta nacional relevante. En 1989, el 20 de agosto fue declarado de nuevo día de San Esteban, entroncándose de esta forma la instauración del nuevo Estado democrático con la más fiel tradición nacionalista y cristiana. Parece ser que en los últimos años el colegio de la Abadía de Pannonhalma se convirtió en semillero de espiritus abiertos, de donde salieron varios de los nombres claves de la apertura y la transición húngara. 


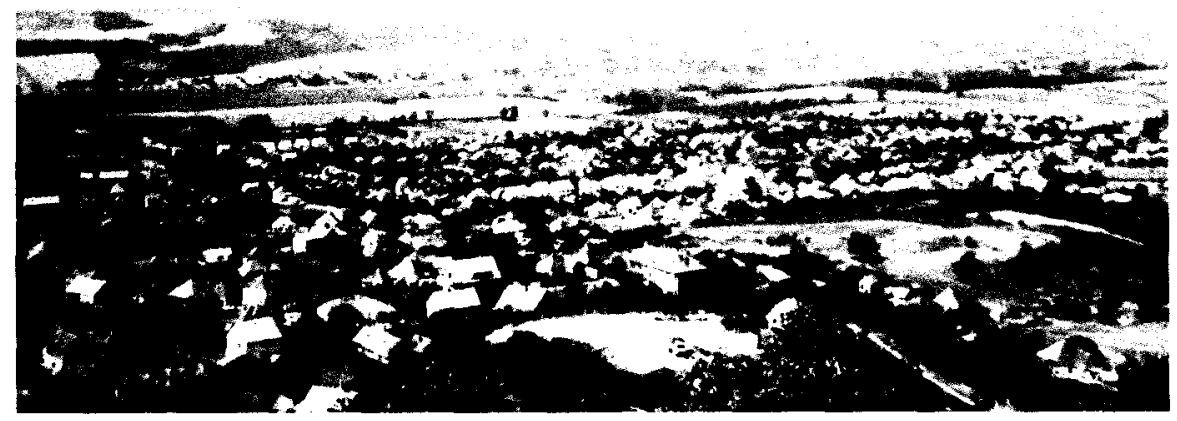

Foto 5. Pueblo situado al pie de la abadia de Pannonhalma que forma parte de la amplia franja rururbana de Györ; las numerosas casas nuevas intercaladas entre las tradicionales es reflejo de la existencia de un sector de población relativamente rico, procedente de los pueblos y pluriempleado en la ciudad. (Foto: Blanca Azcárate).

El Seminario continuó en Miskolc, la capital industrial del Noreste. En el viaje de Györ a Miskolc tuvimos ocasión de visitar Esztergon, ciudad Primada de Hungría y unida al nombre del cardenal Mindszenty, uno de los hombres más carismáticos de los duros años cincuenta; condenado a cadena perpetua en 1949 y liberado en el levantamiento popular de 1956, tuvo que refugiarse en la embajada de EEUU en Budapest; y en ella permaneció hasta 1971, año en que fue exiliado a Viena donde en 1975 murió. En Esztergon, el concejal de cultura nos explicó el papel histórico de la ciudad y el abandono y la postergación sufridos en la época del socialismo, precisamente por su vinculación a la jerarquía católica. Fue privada de su función de capitalidad de la provincia a favor del centro minero de Tatabánya. La transición política ha traído a Esztergon, junto a una fiesta nacional para conmemorar la Revolución de 1956, el nombre de Mindszenty para la plaza de la Catedral, un nuevo plan económico, cultural y urbanistico y una fábrica japonesa de coches pequeños (Suzuki), diseñada con un gran respeto a los valores medioambientales. 


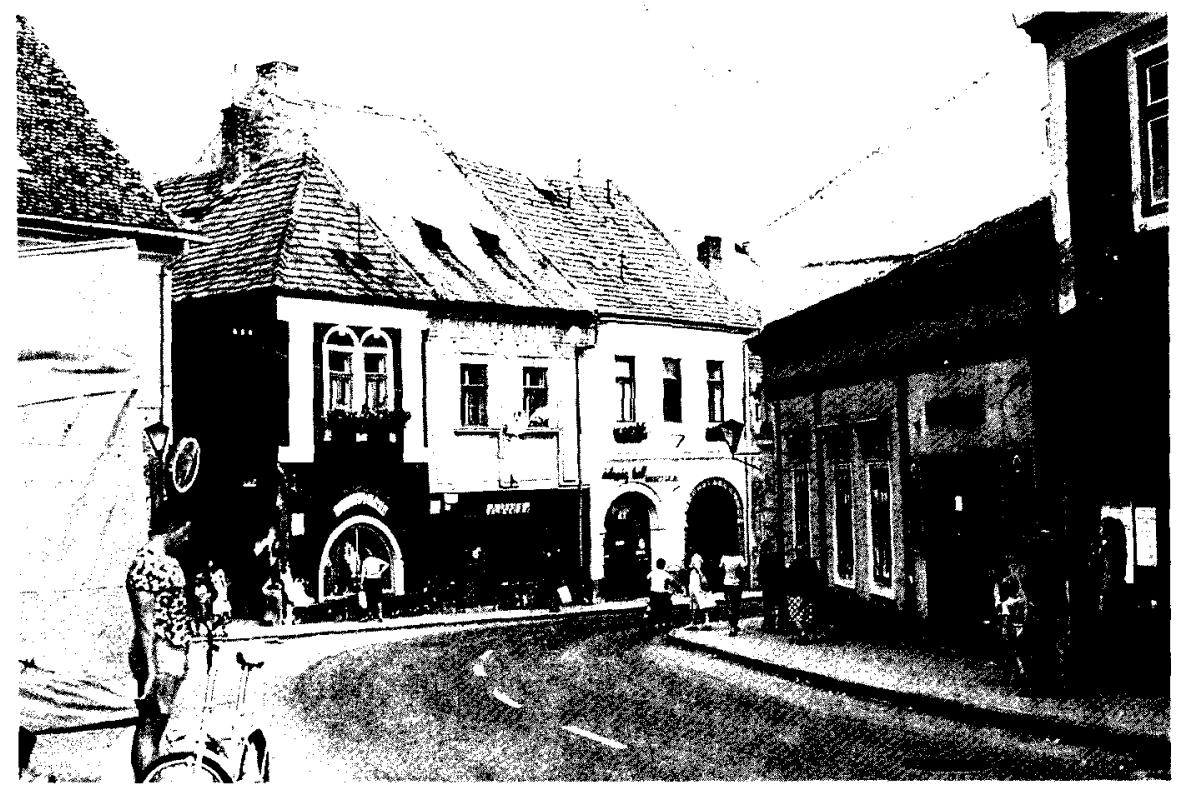

Foto 6. Szentendre es un pueblecito lleno de encanto, situado junto al Danubio, a $26 \mathrm{Km}$ al Norte de Budapest; pertenece a una importante área de segunda residencia que se prolonga hasta Visegrad, en el "codo" del Danubio. (Foto: José Sánchez).

El Codo del Danubio, desde Esztergon a Budapest, es el área más importante de segunda residencia en Hungría, después del lago Balaton, al servicio de las clases medias de Budapest. Visegrad, sede del palacio del gran rey Matias, cuya corte ilustrada era uno de los focos culturales importantes de la Europa Renacentista, y Szentendre (foto 6), un precioso pueblecito de acogedor aire tradicional, son los centros turísticos de visita obligada desde Budapest. Entre Budapest y Miskolc visitamos Eger, ciudad histórica (famosa por su resistencia ante la invasión turca) y arzobispal, núcleo comercial y capital de una provincia vitícola entre los montes Matra y la llanura del Alföld; las obras de rehabilitación de su casco antiguo son, junto con las de Buda y Györ, de las más logradas de toda Hungría (foto 7).

En Miskolc los colegas del Centro de Estudios Regionales nos hablaron de problemas de la industria, de región deprimida, de área periférica 


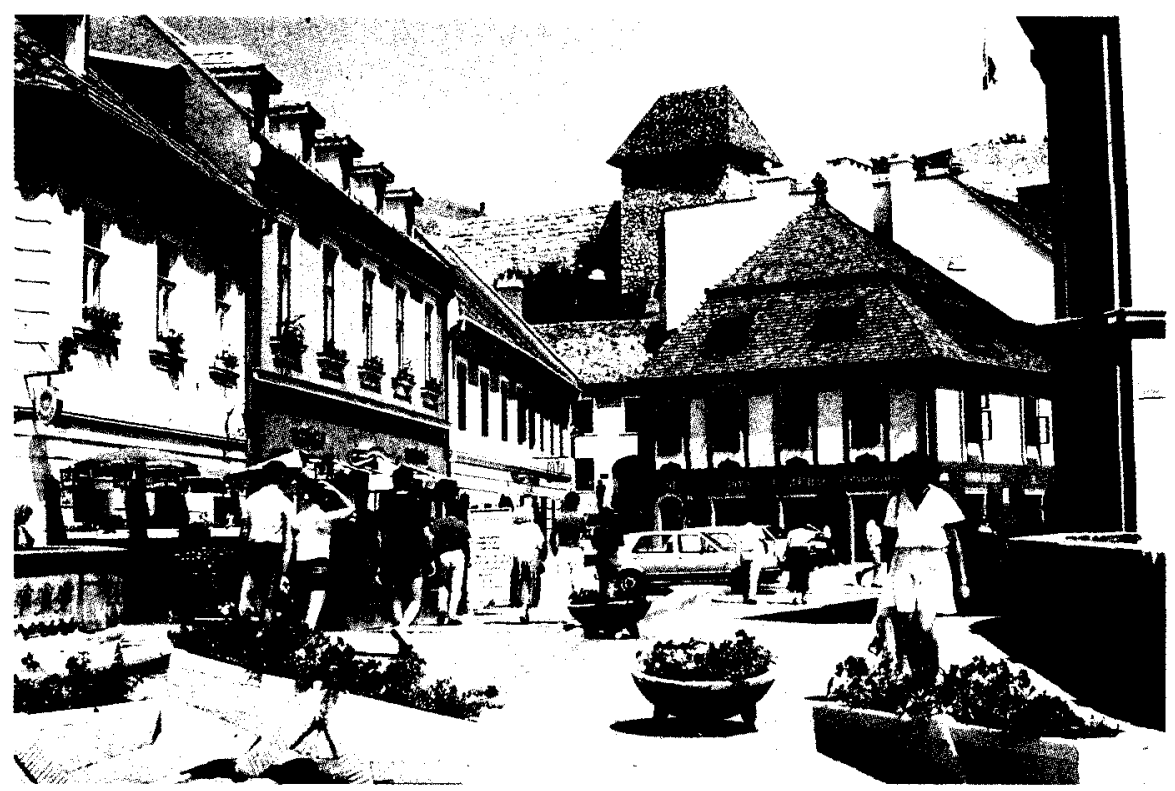

Foto 7. Eger, ciudad histórica, famosa por su resistencia frente a los turcos (120 años de ocupación) y centro de una región vitícola. (Foto: José Sánchez).

y de problemas sociales. Miskolc ( 210.000 habitantes) es el centro de la región que más agudamente ha sufrido la crisis económica derivada de la quiebra en Hungría del sistema socialista. Área de producción de la industria pesada húngara, mimada por las autoridades y tratada durante muchos años como región preferente para las inversiones, zona de inmigración, con ejemplos de nuevas ciudades socialistas, como la de Kacincbarcika, y las ampliaciones de Ózd y Sálgotarján. Tuvimos la ocasión de visitar Ozd - una de las "acropolis" de la industria pesada- para conocer la mayor empresa siderúrgica de Hungria en esta penosa fase de la transición (foto 8).

Györgyi Barta, Directora del centro que el Instituto de Estudios Regionales tiene en Budapest, nos expuso el problema de "Las áreas carboníferas en crisis y su relación con la política económica y energética". Las difíciles condiciones de extracción del carbón se han podido mantener por la política de industrialización forzada, a base de subvenciones estatales y, en los últimos años, de créditos bancarios. Pero la carencia de cualquier otro tipo de fuentes de energía de origen nacional, dan al carbón - aún en estas deficientes condiciones de extracción - un valor de recurso estratégico de gran significación; tanto más cuanto que la 


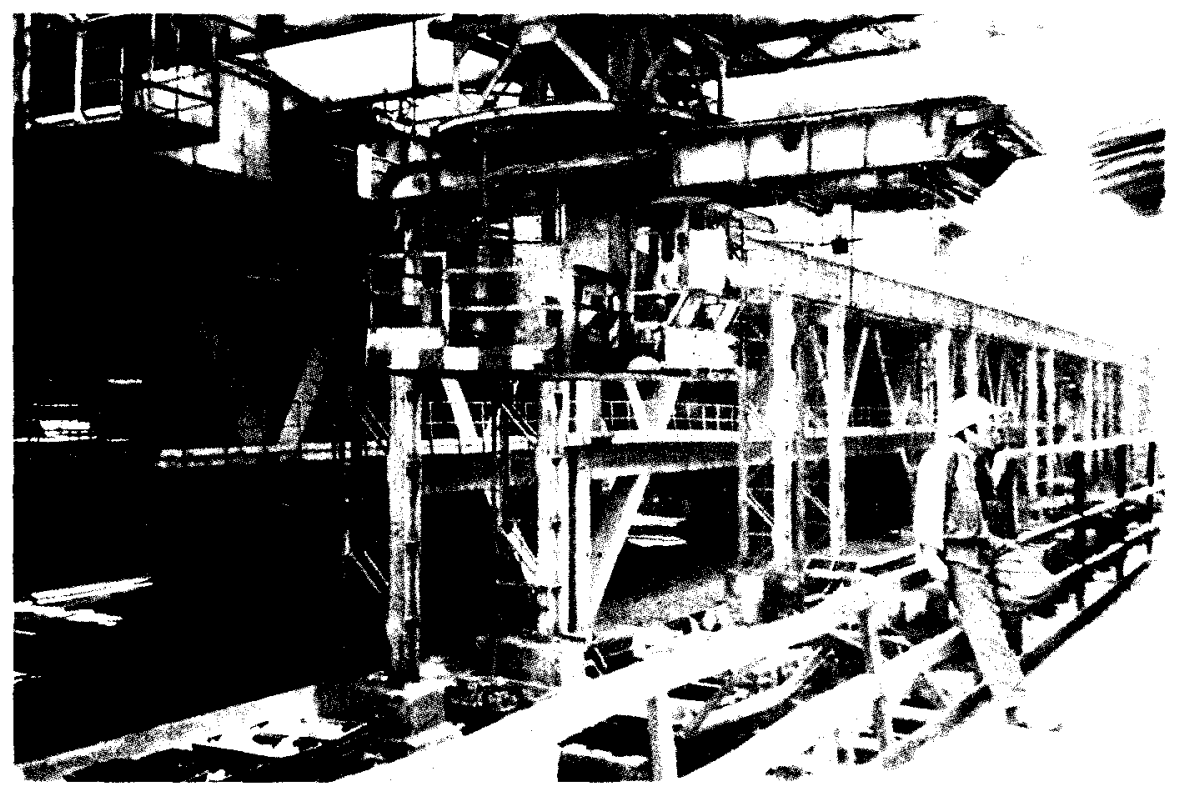

Foto 8. Altos hornos de Ozd, principal centro siderúrgico de Hungria, hoy en estado de reconversión. (Foto: Blanca Azcárate).

URSS ha suprimido desde enero de 1990 el trato de favor que venía concediendo a las Democracias Populares. El cambio de sistema económico lleva consigo el cambio en la política energética y, dentro de ella, en la producción del carbón. Surge así un enfrentamiento entre el gobierno húngaro que, reforzado por las recomendaciones del Banco Mundial, tiene como objetivo hacer de la minería del carbón una actividad rentable -aún a costa de grandes sacrificios-, y las empresas mineras que no quieren asumir los costes económicos y sociales de la reconversión y persiguen las condiciones que les permitan seguir funcionando. En ésta coyuntura, las áreas mineras en crisis ya están perfiladas; entre ellas, la de Nógrad (Noreste) es una de las más afectadas con el posible cierre de todas las minas.

Janós Vincze, Director del centro de Miskolc, nos presentó un modelo para medir el índice de un concepto nuevo que él denominaba "contaminación del medio ambiente social» y hacía alusión a «El papel de los factores humanos en la transformación de la estructura socialm. Preocupado por los problemas sociales, el equipo de investigadores de Miskolc estudian diversos elementos de la geografía social en la región hoy más problemática de Hungria, con los índices de paro más altos, con proble- 
mas de alcoholismo y marginación especialmente graves y un nivel de inseguridad ciudadana alarmante; todo ello inusual en la Hungria socialista hasta hace unos pocos años. El Dr. Vincze nos mostró su modelo mediante unos organigramas que explicaban la relación reciproca entre las actividades sociales y el estado del medio ambiente natural y social. La contaminación del medio ambiente social aparecía asi como un síntoma de los males que padece la sociedad, de las malas condiciones de sus actividades y del bajo nivel de vida. Era como medir el "antibienestarn social. El modelo tenía la ventaja de que mostraba el proceso, las fases y las consecuencias; lo que, desde el punto de vista práctico, facilita la adopción de medidas que pudieran evitar la degradación de la estructura social.

Éva Fekete nos presentó el estudio del área de Cserehát, un típico sector rural deprimido en el Noreste, limitrofe con Checoslovaquia, que sufrió, primero la imposición de la frontera, después el establecimiento del sistema cooperativista de grandes explotaciones, cuando su estructura topográfica no lo aconsejaba, y, por último, el olvido de muchos años por ser considerado como el territorio inútil de la gran región industrial del Noreste. Subrayando su condición periférica, se refirió a la emigración de sus habitantes, muchos de ellos pendulares, que son los más afectados por el despido generalizado de las fábricas. El proceso de descomposición demográfica y el aumento del paro se ven acompañados por el considerable crecimiento de la población gitana. Cserehát aparece así como un ejemplo de las áreas que, a pesar de todas las declaraciones de querer reducir los desequilibrios regionales, han quedado relegadas, sin lograr integrarse en la economía socialista. Como en otros casos, también en Cserehát se confía en que la transición y el cambio político traerá los cambios en los valores territoriales, como la valoración de la pureza del medio ambiente, la forma de vida natural, la agricultura biológica, la proximidad a los centros de innovación,... y la preparación de las nuevas autoridades locales en cuanto a la iniciativa y la autogestión.

El tema de los gitanos, presentes en este área con porcentajes altos en la estructura de la población, fue abordado en la comunicación de Szabó Gyŏrgyné. "Los gitanos y la sociedad en Miskoic"; en ella se expusieron diversas conclusiones sobre la situación social y las posibilidades de integración de los gitanos que componen la colonia de Miskolc.

Los problemas sociales y territoriales que nos expusieron nuestros colegas húngaros, agravados en esta fase de la transición en la que el sistema anterior no funciona porque ya no sirve y el nuevo tampoco porque todavía no está formado, tuvimos ocasión de palparlos en la visita que realizamos a la siderurgia de Ozd. El paso por el corredor de fábri- 
cas de la nueva ciudad socialista de Kacincbarcika nos mostró un ejemplo modélico de paisaje industrial viejo y contaminado. La gran siderurgia, en el centro de la ciudad de Ózd, se había convertido en un grave y espinoso problema para las autoridades económicas de la transición. Ni se podia cerrar, porque acarreaba la ruina de la ciudad, ni se podía mantener abierta, porque ella misma era ya ruinosa. Un intento de venderla a una firma japonesa habia fracasado y uno de sus dirigentes nos explicó los planes, ambiguos y poco convincentes, para salvar aquel gigante siderurgico, orgullo de los tiempos heroicos ya pasados del socialismo. Pero alli mismo tuvimos también la oportunidad de ver y escuchar al que nos pareció primer empresario capitalista húngaro, János Petrenkó (empresa Pekó). Hombre de pueblo y con 25 años de trabajo como obrero en la siderurgia, mostraba un espíritu dinámico y una excepcional capacidad de iniciativa e imaginación: había conseguido del gobierno que le cediese la explotación de una sección de la empresa, el tramo de la fabricación de perfiles de acero. En seis meses había conseguido mantener el empleo, entusiasmar a los trabajadores, conseguir algunos contratos de países occidentales y eliminar las pérdidas que hasta entonces arrastraba la producción; había ampliado la gama de la oferta introduciendo diseños innovadores. Además, para paliar el problema del abastecimiento de productos esenciales de la población. Pekó habia iniciado su penetración en el mundo de los supermercados, con vistas a crear en Hungria una red de establecimientos.

La experiencia fue muy enriquecedora. En unos pocos días el grupo de profesores de la UNED tuvimos la suerte de poder captar en toda su complejidad el momento de "la transición" de un pais socialista a ritmo vertiginoso. Lo que veíamos en los diversos lugares y escuchábamos a los colegas del Instituto de Estudios Regionales y a las autoridades locales nos iba rompiendo poco a poco los moldes de la idea que teníamos forjada de los países del Este y nos permitía comprender mejor el momento histórico que estos países están hoy atravesando y la extrema dificultad de su transición.

Ellos observan también la nuestra con extraordinaria atención. Desde principios de los años ochenta, mucho antes de los acontecimientos de 1989. Hungría ha estado atenta al proceso de nuestro cambio político; presentian que les podría servir de ayuda. Los investigadores del desarrollo-subdesarrollo regional están muy interesados también en la repercusión que la entrada en la Comunidad Económica Europea está tenien- 
do en el desarrollo de nuestras regiones. Hungría no ha dejado nunca de mirar a Occidente, y hoy su meta es integrarse, más tarde o más temprano, en la Comunidad Europea. La experiencia de España, como país periférico y con graves desequilibrios regionales, en este proceso de integración es para ellos muy valiosa. Por eso, nos pidieron que les hablásemos de esas cuestiones.

Tomás Franco presentó el estado de los desequilibrios regionales en España, hablando de las "Desigualdades socioeconómicas tradicionales en las regiones españolas". Los contrastes demográficos y económicos que se observan en España son el resultado de un largo proceso que se inicia en la Edad Moderna y termina con una fuerte concentración de la población y de la riqueza en la franja periférica, con una intensidad de contraste respecto al centro que no se encuentra en ningún otro pais de la Comunidad Europea. Tras el escaso éxito de la política de los Polos de Desarrollo de los años sesenta y principio de los setenta, las regiones españolas han mantenido, incluso agudizado, la grave situación de los desequilibrios que perduran hasta hoy; quizá suavizados por el Fondo de Compensación Interterritorial y con la nueva perspectiva, teóricamente más favorable, que se deriva de la constitución del Estado de las Autonomías y de su incorporación a la Europa Comunitaria.

Sobre estas dos perspectivas trataron las comunicaciones de Antonio Zárate y José Sánchez. El primero, con su comunicación "La incidencia del cambio político en la organización del territorio", se centró en el hecho de que el paso a un régimen político descentralizado ha producido una modificación en la política regional y una nueva estrategia de crecimiento económico del país. En el fondo, la descentralización política es la respuesta a la importancia del fenómeno regional y, no sólo por razones políticas, históricas y culturales, sino también por las importantes diferencias de renta y niveles de vida entre las regiones. Una de las piezas clave en la definición de la nueva política regional lo constituye el Fondo de Compensación Interregional ( $\mathrm{FCl}$ ) que desde 1982 se configuró como un mecanismo de financiación autonómica y como instrumento corrector de desequilibrios. Junto al $\mathrm{FCl}$ completan el esquema de intervención regional el nuevo sistema de incentivos regionales, los planes provinciales y comarcales y el acceso de España al Fondo Europeo de Desarrollo Regional (FEDER), a través de proyectos elaborados por las Regiones Autónomas interesadas.

José Sánchez se refirió a "la política regional de la CEE y su repercusión en España", aludiendo a su resurgir en los últimos años en relación a los nuevos enfoques teóricos, a la incidencia de la crisis económica de los setenta y a la problemática derivada de la ampliación de la Co- 
munidad hacia el Sur; el nacimiento del FEDER y las reorientaciones posteriores; los objetivos prioritarios y las estrategias de desarrollo definidas en la reforma de los Fondos Estructurales Comunitarios (FEC) de 1989. La incorporación de España a la CEE exige la adopción de todo el marco jurídico de la política regional, tanto en lo que se refiere al enfoque y a la instrumentalización, como en la cuantía de los recursos destinados a la corrección de los desequilibrios. Impulsada por los vientos de la CEE, la politica regional se ha visto en España notablemente potenciada.

En este proceso de cambio político y económico, España tiene que realizar un gran esfuerzo para culminar su modernización que, de manera inevitable, pasa por la renovación tecnológica. Por ello, Blanca Azcárate planteó y desarrolló el tema de "Las nuevas tecnológias como posible instrumento corrector de los desequilibrios regionales". El gobierno español está llevando a cabo una serie de iniciativas en el campo de las nuevas tecnologías, con las que espera obtener efectos positivos en la organización del territorio. La exposición se centró en las acciones que se están llevando a cabo en el marco de la Comunidad Europea por las nuevas tecnologías de la información y la comunicación e hizo hincapié en las relaciones entre la aplicación de las nuevas tecnologías y el posible desarrollo regional. Como en otros muchos aspectos, son también notables las desigualdades en la distribución territorial de la innovación tecnológica española, en un contexto general de recursos todavía escasos. Dentro del Programa Marco fijado por la CEE, uno de los más significativos desde el punto de vista regional es el programa STAR (Programa Especial de Telecomunicaciones para el Desarrollo Regional) cuya incidencia en España puede ser muy notable. Por ello, en la exposición se aludió a él de forma más pormenorizada.

Por último, Julián Alonso, director del Departamento de Geografia de la UNED, cerró la serie de nuestras intervenciones con su comunicación “¿Superación o pervivencia de los desequilibrios regionales espanoles?". En ella expuso una serie de hechos y reflexiones en torno a los efectos que la integración de las Comunidades Autónomas españolas en la Europa Comunitaria pudiera tener en la evolución de los desequilibrios regionales. Es evidente, viendo el mapa del Índice Sintético de desarrollo, que las Comunidades Autónomas se hallan en la periferia pobre de Europa. El escaso tiempo transcurrido sólo permite elucubrar sobre el futuro de los desequilibrios regionales; ahora bien, la aplicación de la política regional comunitaria con vistas al Mercado Único y al reforzamiento de la cohesión entre las distintas regiones europeas, invita a pensar en sus efectos beneficiosos. Es necesario un mayor esfuerzo de programación por parte española, teniendo en cuenta que el $85 \%$ del territorio español 
y el $80 \%$ de su población es susceptible de recibir apoyos directos. Sin embargo, dados los bajos niveles actuales de renta de nuestras regiones es previsible que el problema regional español siga subsistiendo durante mucho tiempo en el marco de la Europa Comunitaria, aunque su situación respecto al pasado mejore sensiblemente.

El Seminario terminó con el propósito de mantener los contactos entre investigadores húngaros y españoles. El planteamiento de problemas de desarrollo regional, la presentación de resultados de investigaciones, en análisis de dinámicas territoriales desde el punto de vista histórico y con una perspectiva global, el intercambio de opiniones y el contraste de metodologías, es algo que nos interesa a todos fomentar. El propósito de celebrar en Madrid en II Seminario se vio hecho realidad en la semana del 7 al 12 de octubre de 1991. 